\title{
Design Structure Matrix and Project Management: bibliometric analysis
}

\author{
Isabela Neto Piccirillo, Luis Fernando Magnanini de Almeida, Luciano Queiroz de Araújo Júnior, Sergio Luis da Silva \\ Department of Industrial Engineering, Universiddade Federal de São Carlos - UFSCar \\ e-mails: isapiccirillo@gmail.com; almeida@ufu.br; luciano.qai@gmail.com; sergio@ufscar.br
}

\begin{abstract}
The Design Structure Matrix (DSM), also called dependency structures matrix has been used in different areas. DSM has advantages like simplicity and it can organize the flow of data. Therefore, an area that DSM brings some important benefits is in project management. This tool can identify the cycle that iteration occurs, it also can minimize some revisions that are unnecessary, which accelerates the deliveries. The objective of this paper is to do a bibliometric analysis that focuses on identifying the most co-cited papers about DSM literature (only journals) that is connected with project management. The result shows that DSM can be used with different approaches like traditional, hybrid or agile project management.
\end{abstract}

Keywords: DSM, design structure matrix, project management, bibliometric analysis.

\section{Introduction}

The projects' design and development require the efforts of different participants that results in a complex relationships. Some conventional scheduling and control techniques are used to control the project such as Critical Path Methods (CPM) and Project Evaluation and Review Technique (PERT). However, those traditional tools failed to address interdependency (feedback and iteration) (YASSINE, 2005).

Due to this lack, Steward (1981) introduced the Design Structure Matrix (DSM) to identify dependencies and relations between items to find the most efficient way of sequencing tasks or activities. However, it was not until 1990s that this method received attention by many researchers and practitioners to represent and to analyze the flow of interactions between activities (CHEN; LING; CHEN, 2003). DSM consists of an N-square diagram showing the interaction of each element with the other elements in the model, and it can highlight important patterns in the architectures system such as modules and cycles (BROWNING, 2016; CHEN; LING; CHEN, 2003).

In the project management, it is common to find significant cost (time and money) associated with rework. According to Zhang et al. (2015), DSM can reduce these costs when is used to sequence the project's critical chain, to measure directions and intensities of information flows between activities. Even in innovative projects like New Product Development (NPD), the DSM has been shown a realistic and effective tool for managing (CHEN; LING; CHEN, 2003; DANILOVIC; SANDKULL, 2005).

The aim of this article is to identify the most co-cited papers about DSM literature that is connected with project management.

\section{Literature review}

The DSM provides a simple, compact, and visual representation of a complex system that supports innovative solutions to decomposition and integration problems (BROWNING, 2001).

The structure of the problem is seen as a spreadsheet showing for each requirement to solve the problem what other items it directly depends on (DANILOVIC; SANDKULL, 2005) These relations are mapped in a square matrix with identical row and column labels that shows the dependency of one element on another (GUALBERTO, 2012). The diagonal cells represent the system elements and the off-diagonal cells represent relationships among the elements (BROWNING, 2016).

A sample task-based DSM is illustrated in the Figure 1. The " $\mathrm{X}$ " in the matrix shows tasks interaction. For example, the marked cell at roll 7, column 5, represents an information flow from Task 5 to Task 7 (CHEN; LING; CHEN, 2003).

As you can see in Figure 1, there are three types of task interactions: independent (tasks need to be executed simultaneously), dependent (tasks need to be performed in series) and coupled (tasks need multiple iterations to be completed).

In this way, this method provides insights about how to manage a complex project and highlights issues of information needs and requirements, task sequencing, and iterations (YASSINE, 2005).

According to Gualberto (2012), the DSM also has others advantages like:

- It provides a simple and concise way to represent a complex system; 


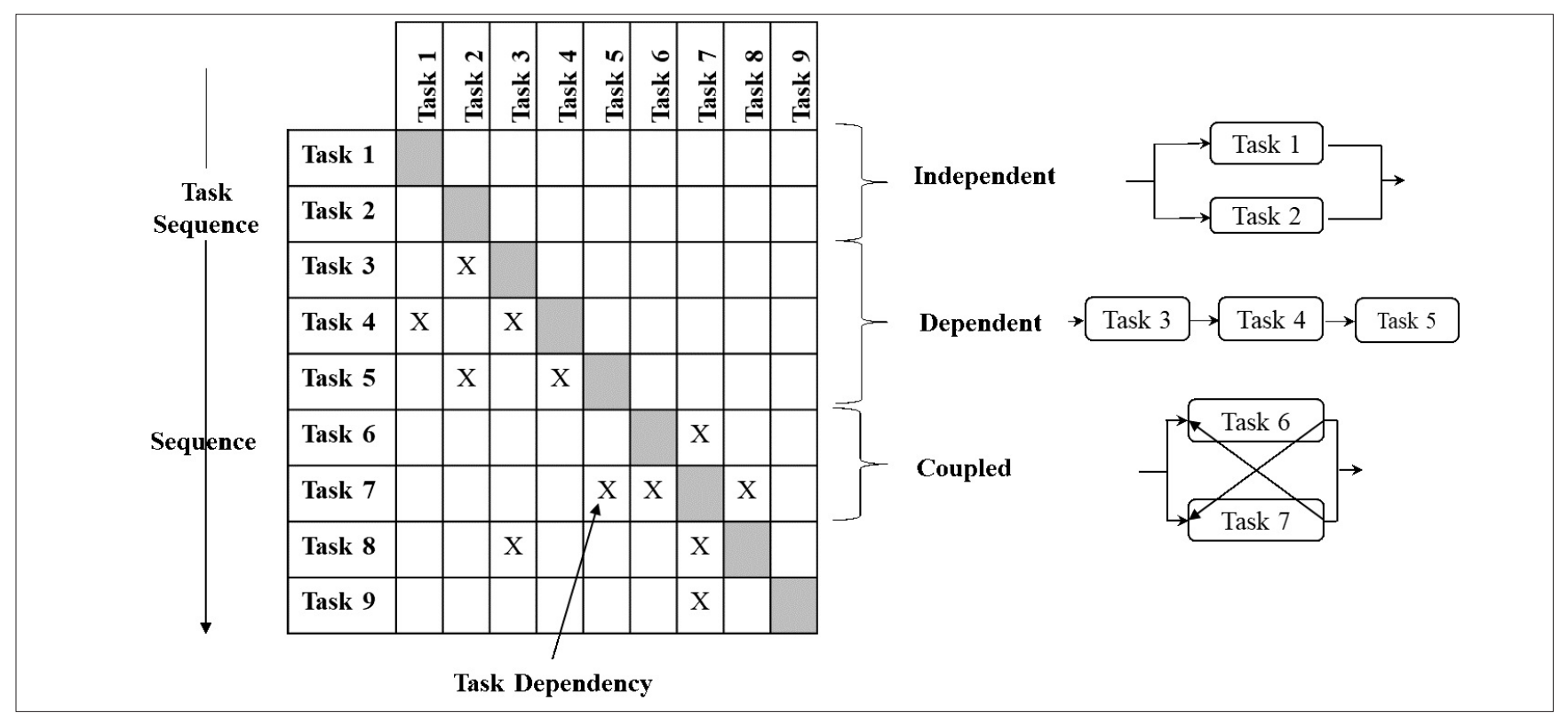

Figure 1. Sample task-based design structure matrix. Source: Chen, Ling and Chen (2003).

- It is amenable to analysis of existing dependencies in the process;

- It can manage schedules and anticipate risks;

- It is a quick and accurate way to examine potential changes to the sequencing of project activities and their effects;

- It provides visually means for capturing, communicating, and organizing activities.

The literature is full of successful DSM implementations in project management including automotive (YASSINE et al., 2000), aerospace (BROWNING; EPPINGER, 2002), construction (GUALBERTO, 2012), telecom (EPPINGER, 2001), and software (MACCORMACK; RUSNAK; BALDWIN, 2006). According to Browning (2016) DSM applications have only recently begun to touch these areas, which offer very promising opportunities for future research.

\section{Research method}

The relevant references were checked through the bibliometric analysis. According to Potter (1981) bibliometric studies are divided into two categories: descriptive (researcher may count and rank the frequencies of articles by countries, authors, journals, year of publication) and citation analysis (researcher may analyzes the most cited papers and the most co-cited paper in a specific field and period of time).

In this research, a citation analysis was conducted to identify the most co-cited papers about DSM that are related with project management. Co-citation analysis describes the frequency that two documents appear in the reference list of a third document (PILKINGTON; MEREDITH, 2009). A cluster analysis was also performed to verify the connection and the proximity among those important papers, as shown in Figure 2 (GARFIELD, 2001).

These relations and clusters can be analyzed through the graphs and edges. Graph is a mathematic structure made by points and edges (BELLIS, 2009). In this bibliometric analysis, graph is made by articles (dots) and the edges connecting them.

These analyzes were made by bibliometric software and the research steps are shown in the Figure 3.

The Sci2 Tool $^{\circledR}$ and Gephi ${ }^{\circledR}$ software were used for the bibliometric analyses. The Sci2 Tool $^{\circledR}$ is the software that imports ".txt" files from the Web of Science database (ISI format) and it generates the network of authors and co-authors. The Gephi ${ }^{\circledR}$ is the free software for visualization and for analysis of networks graphics. Through this software you can explore, manipulate, analyze, build clusters and export network graphics (BASTIAN; HEYMANN; JACOMY 2009).

The input data for this bibliometric analysis were obtained through ISI Web of Knowledge (WOS). The reason of this scientific database was the compatibility with the Sci2 $\mathrm{Tool}^{\circledR}$. The key words established for the papers were: ("DSM" or "design structure matrix" or "Dependency Structure Matrix" or "problem solving matrix" or "design precedence matrix") AND: ("agile" or "apm" or "agile project management" or "scrum" or "project management" or "xp" or "lean agile" or "adaptative software" or "agile method" or "agile methodology" or "agile methodologies"). 


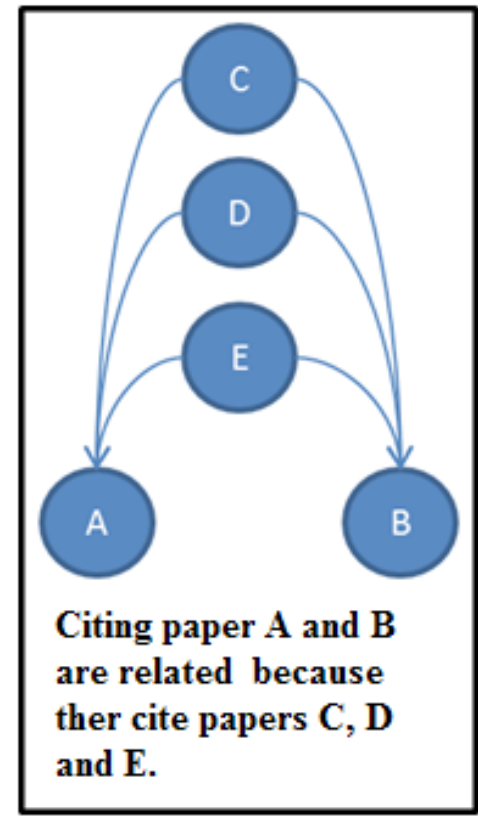

Figure 2. Co-cited analysis. Source: Garfield (2001).

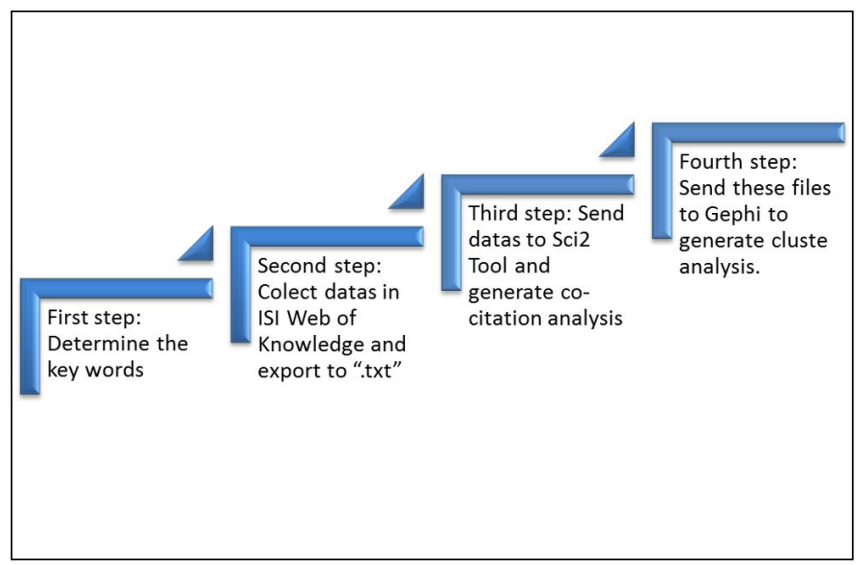

Figure 3. Steps of bibliometric analysis.

\section{The results}

As mentioned, this research was collected in WOS database with the key words showed in the research method. Forty-one papers were imported and they resulted in 949 nodes, 21,182 edges and one cluster. The Table 1 shows the frequency of identify the most co-cited papers about DSM that are related with project management. Only those are discussed in this paper.

Almost all these papers were also found in the co-citation cluster analysis. For better visualization of the cluster, the filter of the degree interval was applied as shown in Figure 4.

As you can see in the Figure 4, there are 13 papers and 11 are also in Table 1. The only paper in the cluster that are not in the Table 1 is the Eppinger et al. (1994), that use DSM for organizing task in product development.

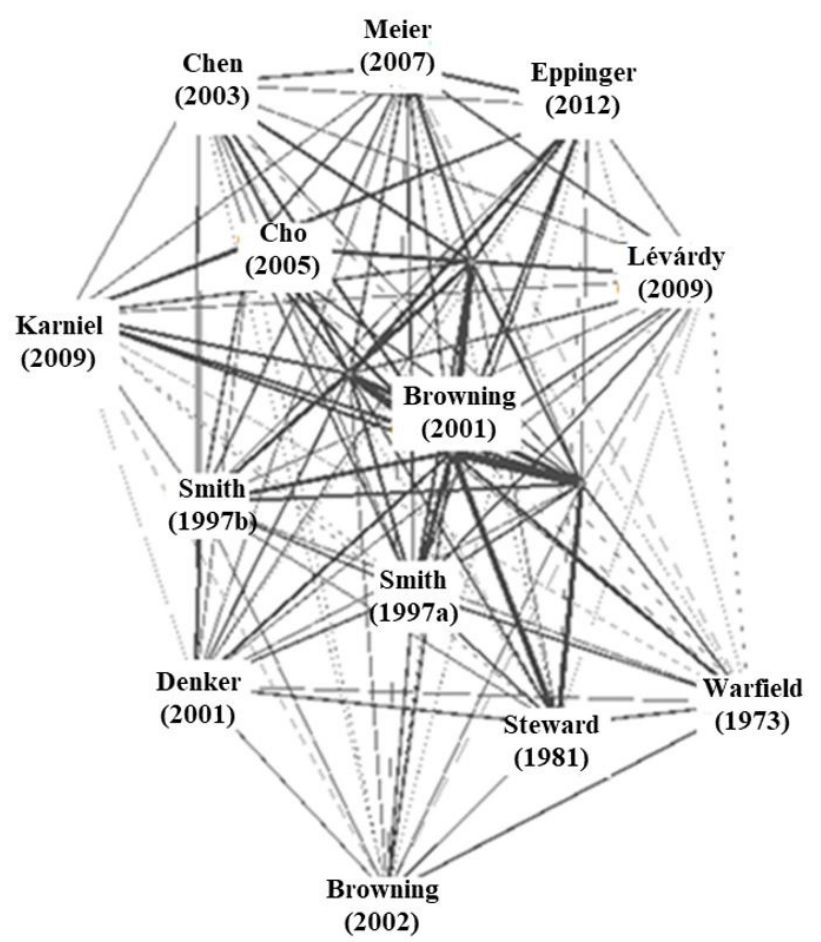

Figure 4. Cluster analysis.

Table 1. The most co-cited papers.

\begin{tabular}{|l|c|}
\hline \multicolumn{1}{|c|}{ Papers } & Frequency \\
\hline Steward (1981) & 30 \\
\hline Smith and Eppinger (1997a) & 15 \\
\hline Eppinger et al. (1994) & 12 \\
\hline Browning (2001) & 11 \\
\hline Cho and Eppinger (2005) & 6 \\
\hline Chen, Ling and Chen (2003) & 6 \\
\hline Eppinger and Browning (2012) & 6 \\
\hline Denker, Steward and Browning (2001) & 5 \\
\hline Meier, Yassine and Browning (2007) & 5 \\
\hline Karniel and Reich (2009) & 5 \\
\hline Lévárdy and Browning (2009) & 4 \\
\hline Warfield (1973) & 4 \\
\hline
\end{tabular}

Some of those papers bring the basis for the theory of Design Structure Matrix. Warfield (1973) brings the primarily tutorial on the use of binary matrices in system modeling. It brings the decomposition of binary matrices into levels such that all feedback is contained. For that, the development procedure partitions the matrix on the basis of supplied data entries and then the interconnections between subsystems are added, allowing the transitivity to be used in the developing the matrix. This method permits one to construct a reachability matrix with computer assistance and to convert it to structural model of a system.

Steward (1981) goes one step further in the method for managing the design of complex system. The author 
argues that systems design involves the determination of interdependent variables that implies in the precedence ordering for the tasks involved in project. Those require planning decisions about how to iterate and where to use estimates is not addressed in conventional planning techniques such as critical path. These techniques can be used to develop an effective plan, showing where estimates are to be used, how to design iterations and reviews and how information flows during the design work. This information flow can also be used to determine the consequences of a change in any variable and which documents must be changed. One special case of process that can use the DSM is the interactive.

Smith and Eppinger (1997a) present a model describing sequential iteration to be used in complex engineering design projects. The model is based upon the design structure matrix representation and assumes that each individual design activity is of deterministic duration with probabilistic repetition, where the repeated probabilities are defined by the strength of the task coupling. This model allows computing the expected duration of the iterative solution process and, suggesting an initial ordering of the coupled design tasks to minimize the expected duration. The model demonstrates that it is better in a sequential iteration process to attempt a task only after the execution of tasks upon which it is strongly dependent, and to attempt the longer tasks later in the design process so the longer tasks are repeated a minimum number of times.

In another paper, Smith and Eppinger (1997b) apply DSM model to an automotive brake-system development process in order to illustrate the model's utility in describing the main features of an actual design process.

On the other hand, Meier, Yassine and Browning (2007) apply Genetic Algorithms (GAs) to an information flow model to find an optimized sequence for a set of design activities. The optimality of a solution depends on the objective of rearrangement. In an activity sequencing context, objectives vary: reducing iteration/feedback, increasing concurrency, reducing development lead-time and cost or some combination of these. They adopted matrix-based representation scheme, the DSM, for the information flow models. Their tests indicate that certain DSM characteristics (e.g., size, sparseness, and sequencing objective) cause serious problems for simple Genetic Algorithm (SGA) designs and to cope with the SGA deficiency, they investigate the use of a competent GA: the ordering messy GA (OmeGA).

Karniel and Reich (2009) identify a gap between the literature concerning activities sequencing based on DSM and the process modeling literature concerning process verification. They made a survey that systematically classifies the approaches used in DSM-based process planning, and discusses their strengths and limitations with problems related to process modeling logic verification of iterative processes.

Thus, the DSM literature had a great development going from binary to higher order matrices and from sequential to iterative processes. Browning (2001), Browning and Eppinger (2002), Eppinger and Browning (2012) address this evolution in their works. The first one is a paper that reviews the use and problems of design structure matrix in decomposition and integration processes. The analysis takes in account two types of DSMs: the static and the time-based. It also consider four DSM applications: (1) component-based or architecture, useful for modeling system component relationships and facilitating appropriate architectural decomposition strategies; (2) Team-Based or Organization $\mathrm{DSM}$, for designing integrated organization structures that account for team interactions; (3) activity-based or schedule DSM, for modeling the information flow among process activities and (4) parameter-based (or low-level schedule), for integrating low-level design processes based on physical design parameter relationships. The paper also makes a discussion of each application and show an industrial example. Lastly, it leads to conclusions regarding the benefits of its use and the barriers to their use and discusses research direction and new applications for DSM.

The second one is a book that makes an introduction of design structure matrix methods and then discusses in detail the use of DSM in products architecture models, organization architecture models, process architecture model and multi-domain architecture models. It also addresses the future of DSM.

The others papers address the use of DSM in project management of product development. Eppinger et al. (1994) present a design management strategy which focuses attention on the essential information transfer requirements of a technical project. This strategy was developed after using the matrix representation to capture the sequence off and the technical relationships among the many design tasks to be performed in order to find alternative sequences and/ or definitions of the tasks to offer opportunities to speed development progress by streamlining the inter-task coordination. Browning and Eppinger (2002) use the DSM for modeling impacts of process architecture on cost and schedule risk in product development. Denker, Steward and Browning (2001) discuss using the dependency structure matrix to design project plans that produce greater concurrency and better iteration management. Chen, Ling and Chen (2003) present a scheduling and rescheduling framework based on Design structure Matrix to deal with the difficult to scheduling and managing the global collaborated new product development process for large projects, especially in sequencing, monitoring and controlling de NPD process. 
Cho and Eppinger (2005) present a process modeling and analysis technique for managing complex design projects using advanced simulations computing. It computes the probability distribution of lead time in a stochastic, resource-constrained project network where iterations take place among sequential, parallel and overlapped tasks. For that, it uses the design structure matrix representation to capture information flows between tasks and uses a simulation-based analysis to account for many realistic aspects discarded in previous analytical models. They propose a heuristic for the stochastic, resource-constrained project scheduling problem in an iterative project network.

Lastly, Lévárdy and Browning (2009) model a product development process as a complex adaptive system. Rather than prescribing which activities will be done and when, they set up: 1) a superset of general classes of activities, each with modes that vary in terms of inputs, duration, cost, and expected benefits; and 2) simple rules for activity mode combination. Thus, instead of rigidly dictating a specific project schedule a priori, they provide a "primordial soup" of activities and simple rules through which the activities can self-organize. Instead of attempting to prescribe an optimal process, they simulate thousands of adaptive cases and let the highest-value process emerge. Analyzing these cases leads to insights regarding the most likely paths (processes) across the project landscape, the patterns of iteration along the paths, and the paths' costs, durations, risks, and values.

\section{Conclusions}

The DSM has been used in project management theory. As it can deal with sequential or iterative process, it could be used for traditional project management, agile project management or hybrid project management. Its use does not replace the other practices of planning and estimation in projects but help them to improve their reliability. The main difference of matrix-based approaches is the concise, visual representation of complex systems.

Even with the development of DSM in the last decades, the theory and mathematical methods have to continue with improvements to deal with the increase of the complexity and dynamic in projects environments.

\section{References}

BASTIAN, M.; HEYMANN, S.; JACOMY, M. Gephi: an open source software for exploring and manipulating networks. In: INTERNATIONAL AAAI CONFERENCE ON WEBLOGS AND SOCIAL MEDIA, 2009, San Jose. Proceedings... Palo Alto: AAAI, 2009. p. 361-362.

BELLIS, N. Bibliometrics and citation analysis. Lanham: The Scarecrow Press, 2009.
BROWNING, T. R. Applying the design structure matrix to system decomposition and integration problems: a review and new directions. IEEE Transactions on Engineering Management, v. 43, n. 3, p. 292-306, 2001.

BROWNING, T. R. Design structure matrix extensions and innovations: a survey and new opportunities. IEEE Transactions on Engineering Management, v. 63, n. 1, p. 27-52, 2016.

BROWNING, T.; EPPINGER, S. Modeling impacts of process architecture on cost and schedule risk in product development. IEEE Transactions on Engineering Management, v. 49, n. 4, p. 428-442, 2002.

CHEN, C. H.; LING, S. F.; CHEN, W. Project scheduling for collaborative product development using DSM. International Journal of Project Management, v. 21, p. 291-299, 2003.

CHO, S. H.; EPPINGER, S. D. A simulation-based process model for managing complex design projects. IEEE Transactions on Engineering Management, v. 52, n. 3, p. 319-328, 2005.

DANILOVIC, M.; SANDKULL, B. The use of dependence structure matrix and domain mapping matrix in managing uncertainty in multiple project situations. International Journal of Project Management, v. 23, p. 193-203, 2005.

DENKER, S.; STEWARD, D.; BROWNING, T. Planning concurrency and managing iteration in projects. Project Management Journal, v. 32, n. 3, p. 31-38, 2001.

EPPINGER, S. D. et al. A model-based method for organizing tasks in product development. Research in Engineering Design, v. 6, p. 1-13, 1994.

EPPINGER, S. D.; BROWNING, T. R. Design structure matrix methods and applications. Cambridge: The MIT Press, 2012.

EPPINGER, S. Innovation at the speed of Innovation. Harvard Business Review, v. 79, p. 149-158, 2001.

GARFIELD, E. From bibliographic coupling to cocitation analysis via algorithmic historio-bibliography. Philadelphia, PA: Drexel University, 2001. A citationist's tribute to Belver C. Griffith.

GUALBERTO, A. C. F. Aplicação da ferramenta DSM Design Structure Matrix ao planejamento do processo de projeto de edificações. 2012. 197 f. Dissertação (Mestrado em Engenharia)-Escola Politécnica, Universidade de São Paulo, São Paulo, 2012.

KARNIEL, A.; REICH, Y. From DSM-based planning to design process simulation: a review of process scheme logic verification issues. IEEE Transactions on Engineering Management, v. 56, n. 4, p. 636-649, 2009. 
LÉVÁRDY, V.; BROWNING, T. R. An adaptive process model to support product development project management. IEEE Transactions on Engineering Management, v. 56, n. 4, p. 600-620, 2009.

MACCORMACK, A.; RUSNAK, J.; BALDWIN, C. Y. Exploring the structure of complex software designs: an empirical study of open source and proprietary code. Management Science, v. 52, p. 1015-1030, 2006.

MEIER, C.; YASSINE, A. A.; BROWNING, T. R. Design process sequencing with competent genetic algorithms. Journal of Mechanical Design, v. 129, p. 566-585, 2007.

PILKINGTON, A.; MEREDITH, J. The evolution of the intellectual structure of operations management 1980-2006: a citation/co-citation analysis. Journal of Operations Management, v. 27, p. 185-202, 2009.

POTTER, W. G. Introduction to bibliometrics. Library Trends, v. 30, p. 5-7, 1981.

SMITH, R. P.; EPPINGER, S. D. A predictive model of sequential iteration in engineering design. Management Science, v. 43, n. 8, p. 1104-1120, 1997a.
SMITH, R. P.; EPPINGER, S. D. Identifying controlling features of engineering design iteration. Management Science, v. 43, n. 3, p. 276-293, 1997 b.

STEWARD, D. V. The design strutucture system: a method for managing the design complex systems. IEEE Transactions on Engineering Management, v. 28, n. 3, p. 71-74, 1981.

WARFIELD, J. N. Binary matrices in system modeling. IEEE Transactions on Systems, Man, and Cybernetics, v. 3, n. 5, p. 441-449, 1973.

YASSINE, A. A. An introduction to modeling and analyzing complex product development processes using the Design Structure Matrix (DSM) method: product development research laboratory. Urbana-Champaign Urbana: University of Illinois, 2005.

YASSINE, A. A. et al. Do-it-right- first-time (DRFT) approach to Design Structure Matrix (DSM) restructuring. In: ASME 2000 INTERNATIONAL DESIGN ENGINEERING TECHNICAL CONFERENCES, 2000, Baltimore, Maryland. Proceedings... ASME, 2000. p. 1-8.

ZHANG, J. et al. Optimization of critical chain sequencing based on activities' information flow interactions. International Journal of Production Research, v. 53, n. 20, p. 6231-6241, 2015. 